\title{
Transforming scholarly practice: embedding technological interventions to support the collaborative analysis of ancient texts
}

\author{
Grace de la Flor ${ }^{1}$ Marina Jirotka ${ }^{2}$ Paul Luff ${ }^{3}$ John Pybus ${ }^{2}$ Ruth \\ Kirkham $^{2}$ \\ ${ }^{1}$ Oxford University Computing Laboratory UK \\ ${ }^{2}$ Oxford e-Research Centre UK \\ ${ }^{3}$ King's College UK \\ grace.de.la.flor@comlab.ox.ac.uk \\ marina.jirotka@oerc.ox.ac.uk \\ paul.luff@kcl.ac.uk \\ john.pybus@oerc.ox.ac.uk \\ ruth.kirkham@oerc.ox.ac.uk
}

\begin{abstract}
Research and Cyberinfrastructure programmes actively promote the development of new forms of scientific practice and collaboration through the implementation of tools and technologies that support distributed collaborative work across geographically dispersed research institutes and laboratories. Whilst originating in scientific domains, we have more recently seen a turn to the design of systems that support research practices in the social sciences and the arts and humanities. Attempts to embed large-scale infrastructures into research settings has brought to the fore the necessity of understanding the knowledge, skills and practices of researchers within a variety of disciplines that might use these technologies. In this paper, we consider an approach to gathering requirements through the introduction of various technical interventions for relatively short term periods so that we may come to an understanding their impact on routine work practices. Drawing upon an analysis of the detailed ways in which classicists work with digital images, we discuss the requirements for systems that support them as they collaborate in the interpretation of particular types of images. We discuss implications for the development of infrastructures to support research collaboration in this area and conclude with reflections upon the experiences gained from conducting naturalistic studies in parallel with design interventions.
\end{abstract}




\section{Introduction}

Over the last decade or so it has increasingly been claimed that scientific research has undergone a major transformation (Foster \& Kesselman, 2004; Taylor, 2001). Advances in parallel processing power made possible through high performance computing have provided the potential to share both data and software applications across multiple sites. Additionally, these advances have enabled the development of virtual research environments (VREs) to support both co-present and distributed collaboration thus creating the potential for the emergence of new forms of scientific research (Atkins et al 2003). e-Science (cyberinfrastructure or $\mathrm{CI}$ in the US) programmes have actively promoted the development of new forms of scientific practice and collaboration by embedding these technologies within research institutes and laboratories. A critical aspect of these geographically distributed scientific enterprises is to provide access to very large data collections, very large scale computing resources and high performance visualization. Whilst originating in the medical, natural and life sciences, this programme of computational research has begun to permeate into the social sciences and the arts and humanities to the extent that a recent e-Science review in the United Kingdom has concluded that the arts and humanities are "poised to achieve large benefit from e-science methods and infrastructure as the human record becomes increasingly digitised..." (Atkins et al 2010: see also Unsworth et al, 2006). In the UK, the term e-Research has in many cases replaced e-Science, reflecting, perhaps, a greater concern with the methodological concerns held by academic disciplines rather than principally focusing on technological innovation (Jirotka et $a l, 2005)$. The success of embedding large-scale infrastructures into research settings, specifically, their uptake and use depends upon understanding what researchers do in their scientific work and how they collaborate with colleagues. Whether they are scientists, social scientists or researchers in the humanities, they rely on particular materials and resources critical to their work. It therefore seems important to understand how such artefacts are used, interpreted and made sense of in researchers' collaborations with colleagues.

In CSCW, considerable work has been undertaken related to these concerns. Workplace studies have been developing an understanding of the knowledge and practices of participants not only in complex workplaces (Luff et al, 2000), but also in domestic (Swan et al, 2008; Crabtree et al, 2002) and public spaces (Vom Lehn et al, 2001; Brown \& Perry, 2002). Of particular interest have been the practices through which artefacts, whether simple documents, conventional computer systems or advanced technologies, are rendered intelligible to colleagues and co-participants. We draw upon this body of work to investigate one of the more recent research areas to consider the embedding of e-Science tools and techniques into an academic environment - the Humanities. Researchers in the humanities work with a wide variety of resources, including texts, audio, 
video, and various media. In this paper we investigate researchers from one discipline in the Humanities - the Classics - and consider the ways in which they collaboratively interpret particular kinds of texts: ancient manuscripts. The projects, of which this study is a part, aim to develop new technologies and research environments to support not only the researchers in question, but also a broader community of classicists. From the outset, it was envisaged that a range of technologies might be applicable including; complex image processing techniques, methods for documenting recent research findings and approaches to communicating both interim and final results to fellow scholars. Additionally, the projects also recognised that analyses of scholars' practices would contribute to the development of requirements for the system, as well as contribute to the evaluation of the proposed technologies.

In this paper we focus on an analysis of the scholars at work as they use a number of technological interventions that have been developed to varying degrees of sophistication. This study enables us to reflect upon how such technologies might support collaboration and also reveals how the texts and the material artefacts that the classicists study are interpreted in and through collaboration amongst researchers with different knowledge and concerns.

The infrastructure being developed does appear to support the scholars in their undertaking of innovative research. Indeed, in the course of the project, they have used these technologies to derive new interpretations of ancient texts. In this case the collaboration between the scholars, afforded by the technology, led to new discoveries and joint publications in the field. In this paper we consider a detailed analysis of their practices, which has led to the identification of functionality to support collaboration through an e-Research system. The capabilities that seemed critical to supporting in situ collaboration did not rely on sophisticated visualisation techniques nor did they seem to require significant transformations in the practices of the scholars. They also raise critical challenges to the typical approaches adopted in the development of tools that might build upon the successes of more local e-Research systems to support a wider community of scholars. It may be that our approach to design, through the introduction of various technical interventions, might point to ways in which current visions of transforming research communication and collaboration through the introduction of new technologies may be reconceptualised.

\section{Technologies for reading ancient texts}

One of the principal ways in which technological support is being developed for researchers in the Humanities in the United Kingdom is through a programme of building Virtual Research Environments (VREs). A key aim of these environments is to provide a shared Internet-enabled resource hub of research applications and communication tools that encourages scholars to collaborate 
across distributed locations. As with many initiatives of this kind, a number of investigative projects have been set up where it seems feasible that advanced technologies can enhance research in particular fields of the Humanities. A related series of projects have been concerned with supporting classicists, principally through the use of novel image processing technologies. The VRESDM project, which ran from 2007 to 2009, was concerned with enhancing collaboration amongst classicists in the analysis of ancient texts, partly by making available digitized images of ancient documents and manuscripts to a wider community. A related project, e-Science and Ancient Documents (eSAD), extends this work with technologies to support the interpretation of ancient texts and provides access to the developing hypotheses and emerging interpretations made by the scholars about the texts. We report findings that have emerged from our studies of various e-Research prototypes developed as a part of VRE-SDM and $\mathrm{eSAD}$ projects that helped shape the requirements for the systems produced as well as assess the potential utility of the technologies developed. In some cases these studies focused on analysis of what could be considered the 'products' of the envisaged infrastructures. In others, we analysed the use of proof-of-concept prototypes developed at the time.

Whilst many of the developments associated with e-Science and CI are relatively new, within the fields of epigraphy (the study of ancient inscriptions) and papyrology (the study of ancient texts written on papyrus or writing-tablets) classicists have been using image-processing technologies for the past 20 years. During this time, infrared image processing techniques have improved the legibility of ancient texts incised on wooden surfaces. More recently a new technique has been introduced where digital images of a physical object are taken using variable directional lighting. After which, a series of algorithms are applied to the image that analyse the shadows cast across the surface at a low elevation (Molton, 2003). This enhances edge detection of the markings within the image making it easier to identify the strokes that constitute each letter on ancient manuscripts. In addition to this, algorithms are being developed that remove additional 'noise', such as woodgrain, which is not an element of the text but rather an artefact of the object on which the text was written. The eSAD project is developing technologies and techniques that make these kinds of enhanced images available to researchers. In addition, efforts are also underway to develop tools that can assist in the analysis activities of epigraphy and papyrology researchers (Bowman et al, 2008). Eventually, the system will offer imageprocessing algorithms, such as brightness and contrast adjustment, illumination correction, and complex techniques for stroke detection and woodgrain removal as features wrapped in one or more Web services. Additionally, the project is exploring the development of an Interpretation Support System (ISS) that aims to keep a record of how ancient manuscripts are transcribed and interpreted (Roued, 2009). This research support system aims to implement features such as: 
databases of standard letter shapes; algorithms for the automatic detection of letters within digital images; letter frequency detection; and character lists aggregated from both ancient manuscripts and the research literature (Terras, 2006). For example, at the conclusion of the project it is hoped to develop a system that can estimate the statistical likelihood of the letters that might appear in a text and to attempt to identify specific letters and words, thereby automating some of the analysis. A further possibility is that researchers could work collaboratively with these texts, both in arriving at an interpretation and in making the results of their work available to geographically distributed colleagues. Here, we consider the practices of a number of distinguished classicists as they analyse images presented in different ways, which display an ancient manuscript. We begin by reviewing an extensive analysis of how the classicists collaboratively analyse projected images of the manuscript, presented in more detail in de la Flor et al (2010). We draw on this analysis to consider how they collaboratively use a more sophisticated prototype technology and discuss the consequences for the design of distributed technologies to support the interpretation of ancient texts.

\section{Methodology and approach}

In our analysis, we focus on the collaborative recognition of letters and words within the manuscript and the ways in which the classicists reach an agreed upon interpretation of the text. So that we may consider the potential of e-Research technology we discuss in detail the collaborative practices of the classicists as they use both projected images and the prototype system to work towards a reinterpretation of a particular ancient manuscript - the Tolsum Tablet.

The studies reported here took place over a period of 6 months, during which time the classicists were concerned with reinterpreting the marks made, nearly 2000 years ago, on the Tolsum Tablet. As well as conducting in-depth interviews with the participants and discussing the variety of artefacts and materials they used in their work, we also attended graduate seminars in papyrology. These helped provide a sense of the scholarly domain under consideration. In addition, we gathered a series of video-recordings of focused activities including; seminars where students analysed texts, a small-scale intervention where classicists worked collaboratively with large enhanced digital images of the manuscript and an intervention where classicists used a prototype e-Research system to analyse different aspects of the same text.

We draw on ethnomethodology (Garfinkel, 1967) and conversation analysis (Sacks, 1992) to analyse the materials we collected. In contrast to how classicists usually work, in the first intervention images of the text were projected onto a large screen. By presenting alterations in the direction of the light source, brightness and contrast, this allowed a group of classicists with differing expertise 
to view a range of images of the same manuscript. Preliminary analysis of this intervention informed the requirements for the prototype e-Research system. In the second intervention a few months later, the classicists engaged in an analysis of the tablet using the prototype, which provides a database of digitized images of ancient documents and manuscripts. The system also includes an associated workspace that aims to provide multiple researchers working in distinct locations the ability to share a common view of a digitized manuscript where they can comment, discuss and annotate areas of the images. We recorded the classicists working in pairs and analysed their interaction with each other and their use of the system. Their discussion provided a resource for understanding not only their interpretative activities around the ancient manuscript but also their use of the system (cf. Suchman 1987, Tang and Minneman 1991, Luff at al. 2006,). In the course of these studies over several months the classicists through their collaboration and detailed readings of the manuscript, began to re-consider earlier interpretations of the Tolsum Tablet. They were supported by the two interventions, and analysis of their work, informed further iterations of the technology's development.

\section{Reading the Tolsum tablet}

The Tolsum tablet is an example of a Roman writing board found in 1914 in a mound in Tolsum in Friesland, a northern province of the Netherlands and dates back to the 1 st Century AD (see Figure 1). These writing boards were inscribed wooden stylus tablets with shallow recesses that were filled with wax. To use the writing tool incisions were made in the wax by a scribe. The wax within the tablet could be smoothed over and reused for rewriting. In most tablets the original wax coating no longer exists and in such cases classicists try to reconstruct the text by deciphering the scratches left by the stilus in the wood after it penetrated the wax (Bowman \& Tomlin, 2005). However, this is not always feasible especially if tablets have degraded significantly or if they were reused for multiple writing purposes resulting in the marks from several texts appearing within it. 


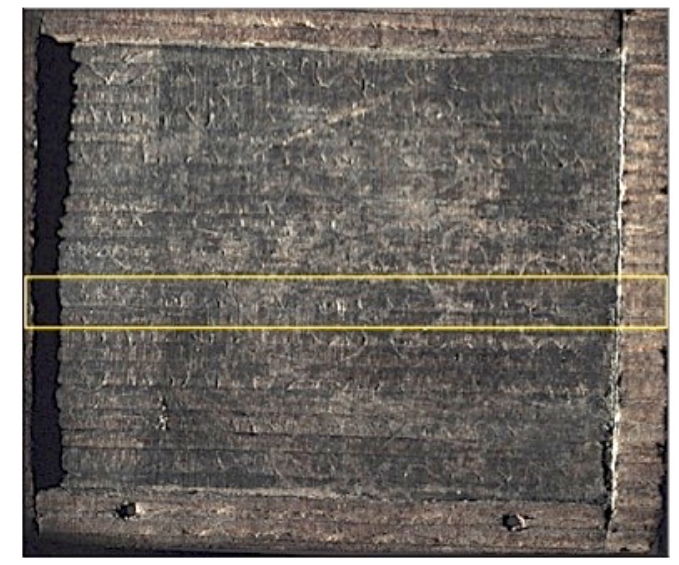

Figure 1. The Tolsum tablet (left) with detail and line 5 highlighted (right).

The Tolsum tablet, was first translated by the scholar Vollgraff in 1917. As is typical of this type of tablet, the front describes its purpose (such as a loan, will, shopping list etc) and includes 10 lines of text (Fig 1., right) with information relevant to the dating of the tablet (for example, the names of Roman consuls). The back of the tablet has 6 lines of text (Fig 1., left) and includes the signatures of participants and witnesses. In this study we focus on the activities involved in analysing the front of the tablet.

To get an idea of the types and quality of marks on the manuscript that the classicists are working on, we present an example of Vollgraff's transcription highlighted on the right of Figure 1, where Vollgraff reads the 5th line of the tablet as: EMI TESTE CESIDIO C(ENTURION)I. This loosely translates from Latin as the witnessing of a sale of a certain amount. Above it, in line 4, Vollgraff translated the line as 'RITE UTI LICET BOVEM', referring to an ox ('BOVEM'). Hence, Vollgraff interpreted the text as the sale of an ox between a local resident and a Roman citizen.

For many years this tablet was the northernmost of its kind to be translated and considered important because it could be related to a revolt in Frisia in AD 28, as reported by Tacitus, that was associated with the taxation of ox hides (Bowman et $a l$, 2009). Making this connection between the Tolsum tablet and the 28AD revolt clearly depends on achieving a degree of certainty about the dating of the tablet, which scholars had variously suggested could be between AD 29 and 116 (ibid). For the classicists involved in our project, it seemed that image processing techniques applied to digital images taken of the tablet could assist with its reexamination, particularly with regard to a more accurate indication of its date. As can be seen from Figure 1, the text of the tablet is barely legible. One way of resolving illegibility in traditional practice, when working directly with a wooden tablet, is that classicists will attempt to tilt the tablet in various directions in order to steer the ways in which light and shadow are cast upon its incised surface. This tilting of the tablet in relation to lighting may make letters, words and lines of text 
legible (Bowman \& Tomlin, 2005). However, with the introduction of digital images variable directional lighting can simulate this technique to some extent (Molton et al, 2003). Additionally, image processing could also reduce the visibility of the woodgrain making it possible to distinguish the marks made on it more easily (Tarte, 2009).

\section{Seeing through the image to the text}

In order to recognize the details of possible words and phrases, the classicists need to identify the ways in which ambiguous shapes within the manuscript might form letters. These activities occur within the context of iterative readings of the entire text that transform their interpretation of its purpose and meaning as letters and words are identified and agreed upon. Letters can be illegible or uncertain for many reasons, for example because of damage or the tablet being used many times for more than one purpose. It should also be noted that although some letters have standard forms, there may be great variety in how letters are written, some of which depend on the period at which the text was produced. For example, there are significant differences in the way in which all the letters in the alphabet were written between the 1st century and the 4th century AD (and later). Furthermore, whilst following the conventions of the day, each scribe's personal writing style may vary widely. This makes the identification of the generic writing style (and, for some scholars, even the particular style of the scribe), crucial to the transcription of the text.

Take for example the following fragment, where Rupert, Axel and Colin, three experts in epigraphy, are sitting at a desk looking at paper copies of the new images of the tablet along with Vollgraff's 1917 translation. Each researcher has his own area of expertise; Axel specializes in Latin, Roman History and Papyrology (the study of ancient literature and its meaning). Rupert specializes in Latin and Palaeography (the study of ancient handwriting) and Colin specializes in Greek and the study of ancient inscriptions produced in stone. While they conduct their analysis of the tablet, high-resolution digital images of it, produced through image analysis, are projected on to a large screen. At this point in their discussion Rupert raises some doubts about Vollgraff's reading of the first two words in line 4 ('EMI TESTE').

Rupert Colin

Axel

$R$ : Actually, $>$ I think in the next line $<$ where they read 'TESTE' I was gunna read that as 'RES' (.3) Umm, you got 'E' 'M' (.3) And >thennit< loo:ks (.8) Ah, in line $5(.3)$ Umm, and thennit loo:ks (.) >terribly like one $<$ of these 'R's $\uparrow$ again (.) 
... I'm at line I think it's $\downarrow$ her:e
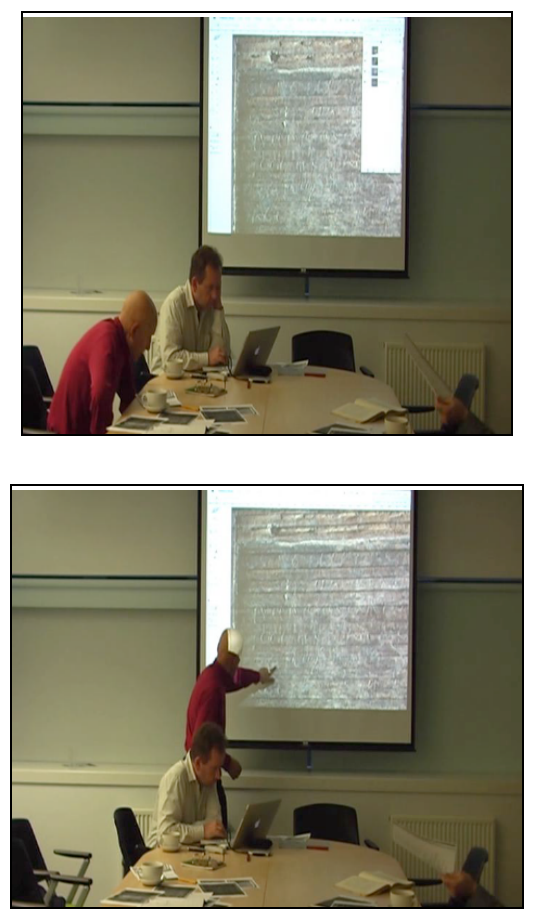

Figure 2. Re-interpreting Vollgraff's 1917 translation.

Rupert's new reading of 'TESTE' as 'RES' is based upon the identification of a non-standard form of the letter 'R'. As seen in Figure 3, when compared with the standard form of the letter 'R' (Figure 3, on the left) the Tolsum tablet 'R' (Figure 3 , on the right) is indeed atypical.

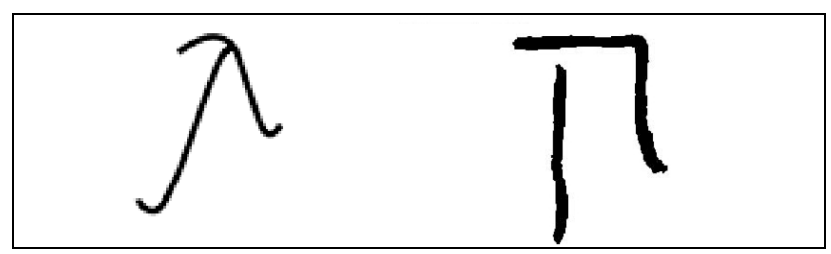

Figure 3. The standard (left) and the Tolsum 'R' (right)

Through the collaborative deciphering process the classicists begin to make sense of the writing produced on the tablet and repeatedly reassess, each line of the tablet as they talk and gesture over the projected images. With each iterative pass the focus of analysis may change according to the arising concerns of the classicists in a "first-time-through-again" manner (cf. Garfinkel et al, 1981). As mentioned previously, for over 90 years the text was thought to be the sale of an ox between local residents and a Roman citizen. However, the new reading of the second word in line 5 of the tablet does not support this. The transformation of the word 'TESTE', which translates as witness, into 'RES' - a thing, object or event has implications for the purpose and hence the meaning of other words that appear in relation to it within the tablet. In their doing of textual analysis, the classicists attempt to retrace the historical context and purpose of the tablet and 
thus orient to the digital image not simply as a representation of the manuscript, but as a way in which to access the text that resides within it.

As the classicists explained in interviews, their analysis of ancient manuscripts is akin to 'trying to solve a crossword puzzle' and has been compared to detective work and a process of piecing together clues (Terras, 2006). Significantly, the classicists have identified the letter ' $R$ ' found within the manuscript to be unique to the scribe's hand, not following the conventions of the time. This newly identified, atypical letter-form has immediate implications for ways in which other letters and words within the tablet might be re-interpreted.

In addition to conducting an analysis of the text using digital images, the classicists' also try to understand the material characteristics of stilus incised wooden tablets. Indeed, when analysing tablets some classicists, including Rupert, are known to use wax tablet models in order to recreate the motion of the stilus on a piece of soft wax similar to the kind used for Roman writing. Like other kinds of text analysis, the classicists are attempting to understand how the text was produced. For the classicists, the material qualities of letter production including the ways in which the scribe may have pressed the stilus across the tablet and the angles used to produce markings in the wax are integral to letter and word recognition. The classicists' gestures replicating the use of the stilus reveal how crucial the scribe's embodied production of letters are in their interpretive practice and when working on projected images of the tablet the classicists draw upon an understanding of the complex embodied practices of writing to understand how the texts were produced.

Whilst the classicists rely upon their expertise to assess a scribe's writing style when interpreting an ancient text, they also keep in mind the ways in which handwriting conventions evolve over time. Conventions in Roman cursive handwriting are divided into two periods: Old Roman Cursive (ORC), which was used from approximately the 1 st century $\mathrm{BC}$ to the end of the 3rd century AD, and the later New Roman Cursive (NRC) from approximately the 3rd century to the 7th century AD. With regard to the Tolsum tablet, even given the variation in the literature about its dating, the classicists would expect the tablet to be written in ORC. In all but one instance, Vollgraff had interpreted a recurring combination of marks (Figure 4a) as an 'E'. However, this was a highly unusual interpretation because the letter ' $E$ ' is normally identified by two vertical lines (4b). In one instance, on the back of the tablet, Vollgraff read the shape in 4a as an 'A' (which would usually be written as in 4c). This one exception of Vollgraff's, interpreting the shape as ' $\mathrm{A}$ ', led the classicists to reconsider all instances of that letter-form wherever it occurred. 


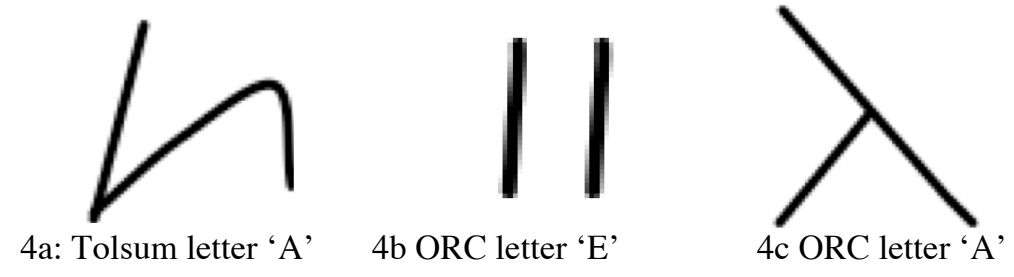

Figure 4. Locating another 'A'.

When Axel comments on this difference he traces over an area of the projected image with the index finger of his right hand. He points to the letter and traces over the projected image twice with his finger. With each trace his gestures animate the shape seen in Fig. 5 (right). As he traces, the shape of this gesture does not reflect a 1st century 'A', but something different. Old Roman Cursive 'A's are typically considered to appear in the form given in Figure 5 (left), whereas the letter in Figure 5 (right), attributed to the scribe's hand, has characteristics of later forms of the letter 'A'.

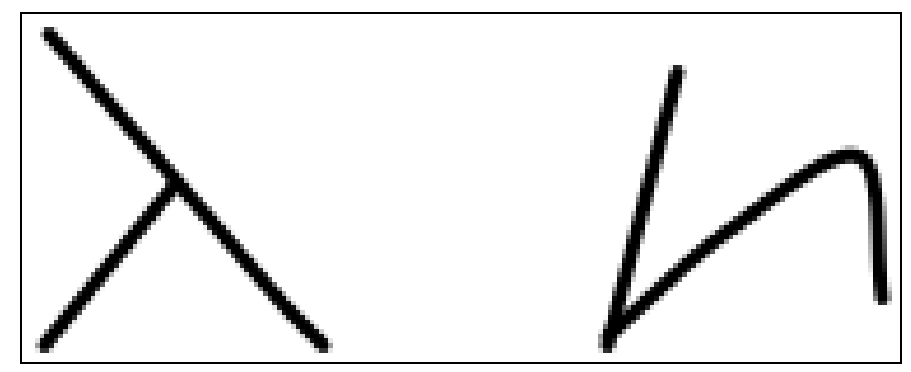

Figure 5 . The $1^{\text {st }}$ century (left) and the Tolsum letter 'A' (right)

Axel's gesture matches more closely the curves of the scribe's 'A', in other words, a later form of 'A'. As he sits down he mentions some consequences of this new reading of the letter.

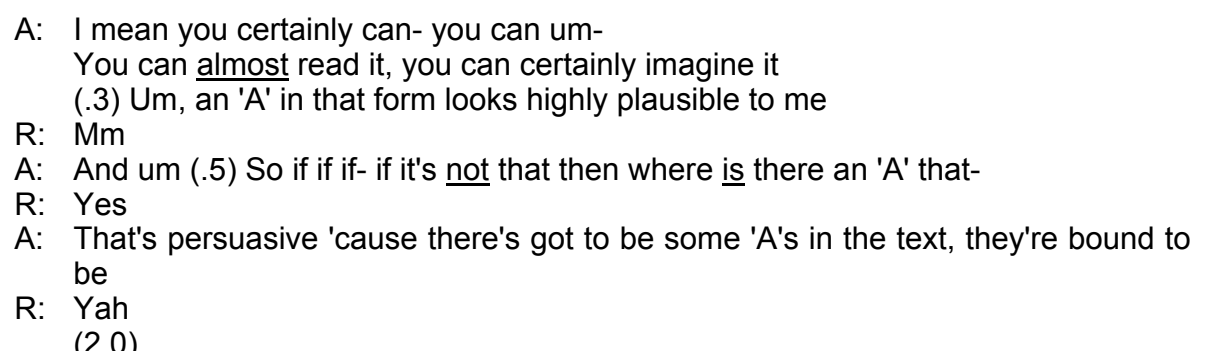

Here, Axel moves from a detailed analysis of the letter-form to a wider view of the implications of the letter within the context of the tablet as a whole, where his question could be understood as; if ' $\mathrm{A}$ ' is a commonly used letter, and if the letterform he has pointed to is not an A, where are the As in the text? Rupert supports this with an observation about the 'E's. 
C: ((laughs))

R: (And) there are some perfectly good 'E's of-

A: Yea

R: Of a different form-

A: I think that's right. I think that must be an 'A'

$\mathrm{R}: \mathrm{Mm}$

(1.0)

A: Mmmm (1.0) So, it's a 4th century 'A' in a 1st century text

Rupert provides an additional piece of evidence for Vollgraff's ' $E$ ' being reread as an 'A'; 'E's of the more standard form (the two lines seen in Figure 4b) have already been identified elsewhere in the text. They appear to infer that perhaps the letter pointed to by Axel is not an ' $E$ ' as Vollgraff had read it.

The classicists have a number of questions to resolve regarding Vollgraff's 1917 reading of the tablet. The crucial ones being why would there be two different forms of the letter ' $\mathrm{E}$ ' and where are the 'A's in the text? A resolution to this quandary, and one that is made by the classicists here, would be to reinterpret the unusual forms of the letter ' $E$ ' and read them as 'A's. The result of which would be quite a different reading of the words that include this letter and a re-interpretation of the entire text within the tablet. More critically, a discovery has taken place with this re-reading of the letter; 'A's with a 4th century likeness have been found written within a 1 st century text.

The classicists rely on more than the visual appearance of the markings on the digital image to interpret the letters. The work of analysing ancient manuscripts has been described as not a performance of "a letter-by-letter transcription like sleepwalkers, but a wakeful testing of possibilities in the light of other knowledge" (Bowman \& Tomlin, 2005). Their ability to identify atypical letterforms and anomalies within the manuscript depends upon their experience and expertise in identifying variations in handwriting, along with their ability to read intuitively and imagine how letter combinations may form intelligible words. Additionally, they rely upon their knowledge of Latin, Roman History, Papyrology, Palaeography and other areas in the Classics. With this background they are able to make informed guesses about the likely frequency of certain letters appearing in the text, as well as how particular types of text, such as wills, loans, sales receipts, shopping lists, etc. are formatted. For example, in this tablet, the opening line where the date and names appear, provides clues about the purpose of the text and therefore what its meaning might be. As Sharrock \& Coulter (1998) suggest rather than considering the interpretation of images with regard to an individual's perceptual capacities, viewers draw upon a "vernacular intelligibility", gained through years of training and hands-on-experience, in this case, of ancient manuscripts. The classicists in this study make quite a surprising discovery in the re-reading of the tablet. Through their analysis they develop a distinctive interpretation not only of the text's meaning, but also of the emergence of conventions in writing within the first century. 


\subsection{The role of re-inscription in the interpretation of ancient texts}

The identification of the letters inscribed on the Tolsum tablet and the interpretation of words, sentences and the entire text, are not distinct activities that occur in a linear fashion. Rather, seeing markings and grouping them together to identify which letter they make up, as in the section above where Rupert's new reading of 'TESTE' as 'RES' is based upon the identification of a non-standard form of the letter 'R', occurs against the background of a proposed interpretation ('RES'), which goes against the current interpretation ('TESTE'). The new interpretation requires that the last two letters 'TE' no longer be seen as grouped together with 'T/RES'. Later, these letters are re-identified and re-interpreted as 'PE' and joined with an entirely different word that follows after the newly identified 'RES'. This activity occurs at the level of letters and words as well as at the level of the whole text. Considerations of the purpose of the text, for example, whether it be a document for the sale of an ox or a legal contract, also serve to give weight to specific hypothesis related to letter identification. These require historical knowledge concerning the social, economic and political context in which the text was inscribed, or the purpose that it was meant to fulfil. Thus, interpreting texts relies on being able to shifts between different kinds of reading, ranging from the reading of letters and the markings that form them, to reading of the entire text with respect to the historical setting in which it was written. The classicists propose possible interpretations and test their hypotheses by constantly contextualizing and re-contextualising the text at different levels of analysis.

Through their readings and interpretations, the classicists' arrive at a reconstruction of the text within the tablet. In the previous fragments we saw the classicists re-enacting the production of letters in relation to the image of the text projected on the screen. In the following instance, instead of tracing on top of the projected image Rupert draws the proposed letter on a piece of paper (these paper drawings are referred to as mock-ups by the classicists) and expresses his initial doubts about its characteristics, particularly in relation to differences in writing conventions between the 1 st and 4th centuries:

R: I mean, suppose (he)'s doing an 'A' like this (.) with a- with a- (.) How would it be? With ah diagonal down stroke and he's sort of coming up again and he's got some getting up to that (.) he's actually (.) doing that $(.3)$

... I mean, it's a change that occurs much later, but-

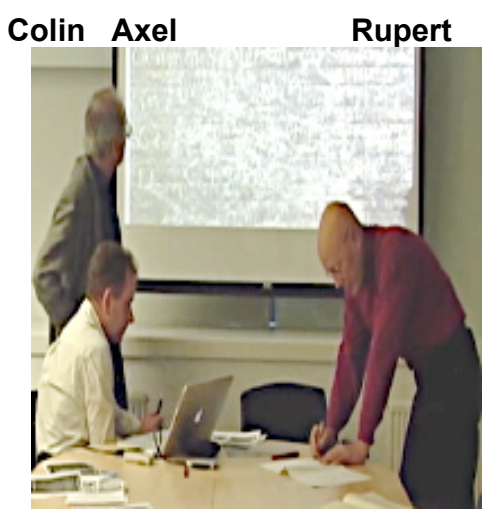


Figure 6. Reconstructing the text within the image.

The 'later' being referred to here is the historical context (e.g. the 4th century). Axel responds to Rupert's initial doubts with "Well, it's only a late looking 'A' because we think it's a late looking 'A' ". Through his drawing, Rupert produces a re-inscription of the letter revealing details of how the text was produced not available in the image. The classicists go on to produce other textual mock-ups of the ancient manuscript that make more apparent letter-forms less ambiguous. These paper mock-ups are Latin transliterations of letters and words that reside within the digital image and culminate in a line-by-line re-interpretation of the entire text (Figure 7, left). Added to these mock-ups is commentary which accompanies their re-interpretation, thus providing further historical evidence and references to the literature.

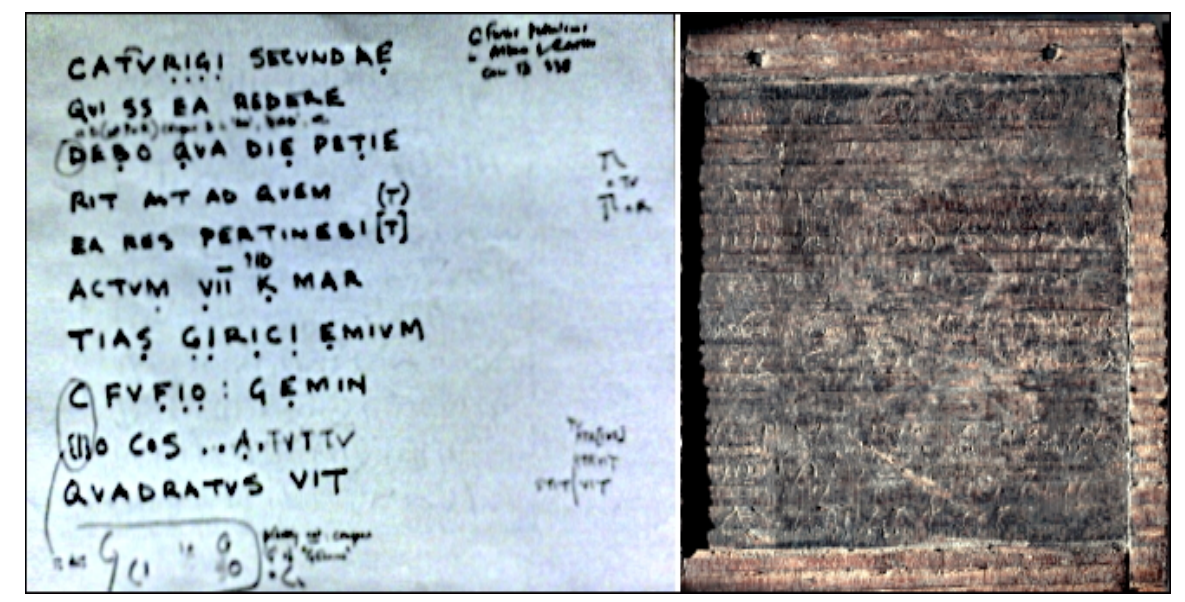

Figure 7. A working re-inscription and the digital image.

Through the activity of re-inscription the classicists arrive at a working reinterpretation of the text and in this way attempt to see through the image to the text. With the juxtaposition of both the mock-up of the manuscript's text and the digital image of the manuscript, the classicists are able to work simultaneously with the text as a whole whilst also focusing on specific letters and words; this is in addition to keeping track of various inferences they have made about individual letters.

With the simple means of projecting the results of enhanced images onto a screen, classicists from different sub-fields are able to work together and discuss different readings and their consequences. An epigraphist can propose an unexpected form of the letter ' $\mathrm{A}$ ' for example, as well as discuss the ways in which it may have been written by a scribe using a stilus and as a result, raise issues that such a reading may have for the text as a whole. By working together whilst co-located differing proposals can be immediately juxtaposed and compared with each other. In this case, the projection of the enhanced images 
allowed the classicists to work together to re-interpret the text and to identify different readings of letter-forms and the text as a whole. This initial intervention also led to a number of requirements that informed the design of a prototype system for VRE-SDM.

\section{Designing an e-Research system}

Drawing from preliminary studies of the work of classicists detailed above conducted within a broader requirements gathering process (cf. Bowman et al, 2008), a prototype system was designed that provided the project team with an opportunity to develop some of its core functionality. It was clear that the functionality the classicists needed was a means to display and annotate images. More specifically, the system would need to allow images to be viewed in different ways including:

- Select different images of the same tablet that varied in brightness and contrast. This reflects their selection of different digital images that were projected on to the screen.

- Compare images and to adjust the contrast and brightness of each image, and parts of the image, individually. After selecting the different images for projection, the classicists would often compare them to each other in order to produce an analysis of the manuscript.

- Zoom in to detailed areas of the image as well as to zoom out to view the entire manuscript and to toggle from small screen to full.

From the analysis of the classicists viewing the images in situ it also seemed desirable to provide a resource for collaborative pointing and sharing and where users could have a private view of the workspace whilst also being able to shift to a shared interactive view at any point.

It was recognized that classicists would need to annotate images and to view partial transcriptions of the text alongside images, in some way to reproduce the type of activity that was achieved through the drawing of mock-ups. This ability to annotate images became a critical part of the functionality of the system. It needed to be optional but also suggested further capabilities such as being able to provide a chronological list of annotations, to create a threaded list of annotations and to tag groups of annotations. It also seemed important to provide separate fields for transcriptions that were distinct from annotations and notes in order for classicists to view them alongside the highlighted letters and words. At a later stage it might also be possible to also emulate the scribe's writing action in some way, re-producing the angle and pressure with which scribe created letter strokes, for example, to allow scholars to write the forms on paper (via an Anoto pen ${ }^{1}$,

1 Anoto Group AB, http://www.anoto.com 
graphics tablet or tablet PC). The initial requirements exercises led to some suggestions for more complex software processing, for example to be able to

- Allow for integrated searches across important well-known databanks of texts and images ${ }^{2}$.

- Provide a letter comparison tool to compare, for example, one instance of ' $E$ ' with another instance 'E'. Possibly layer them over each other or provide a databank of 'E's. Potentially provide a databank of characters from both the Latin and Greek alphabets: e.g. personalised grid-like interfaces where researchers could drag letters from digitized texts into each grid they create in order to build up a custom alphabet for the manuscripts they are analysing. These grids could then be stored for cross searching.

- Allow for additional information about manuscripts, including their archaeological context (online where possible) and connect with related literature, citations and other historical artefacts.

These requirements were developed through the analysis of the collaborative interpretive practices of the classicists particularly the ways in which they identify markings more clearly and most importantly how they see and read the text that resides within the digital image. For the initial design of the e-Research system a selection of capabilities would be made available through a Web-based interface. The prototype was then evaluated in order to identify how well their routine activities were supported.

\section{Prototype evaluation}

The VRE for the Study of Documents and Manuscripts (VRE-SDM) was developed through a series of four iterations, each of which was presented to the classicists for feedback and prioritization of feature development. In addition to providing reflective feedback during demonstrations of software, the classicists also had an opportunity to evaluate the system in actual workplace contexts. Drawing on the approach taken in Suchman's study of the use of photocopiers (Suchman, 1987), we asked the classicists to use the system to try and conduct their everyday activities when analysing manuscripts. The prototype VRE, at the time of its evaluation, consists of a mouse and keyboard driven system that provides a workspace where classicists can select high-resolution digital images which can be manipulated and viewed alongside other images, texts and annotations (see Figure 8). The system includes functionality that can magnify detailed areas of an image as well as provide an overhead view in which to see an

2 For example, Duke Databank of Documentary Papyri, Heidelberger Gesamtverzeichnis, APIS, Vindolanda Tablets Online, databases of Greek and Latin inscriptions; and on-line reference resources, dictionaries, Lexicon of Greek Personal Names, LDAB, Fayum Villages Database, etc. 
image in its entirety (see Figure 11). The system also includes an annotation feature, making it possible for the classicists to comment on and translate letters, words and phrases.

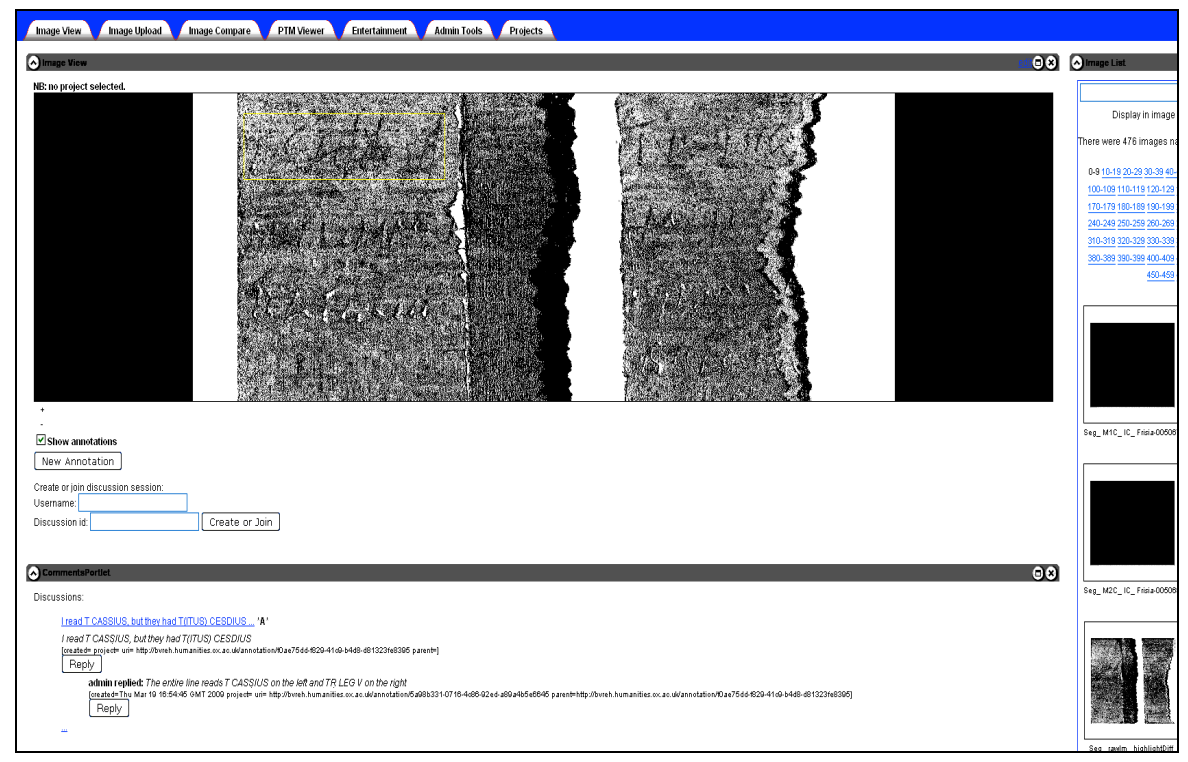

Figure 8. The VRE-SDM prototype system.

During the evaluation session the classicists conducted further analyses of the front of the Tolsum tablet where they viewed two images side-by-side, each with different contrast and brightness settings adjusted to identify letters, words and phrases. As they worked with the VRE, the classicists annotated areas of the manuscript in order both to identify and provide justifications for the re-reading of words and their associated letters, as well as provide a re-reading of the manuscript's date. When they performed their analysis of the tablet using the VRE they brought with them various mock-ups and notes from the previous in situ sessions. This material was referenced in order to recall and comment upon some of the work that they had done previously. The classicists collaboratively annotated areas of the manuscript; they examined the word 'QUEM' with its rereading from 'BOEUM', and the word 'AD' with its re-reading from 'IL'. The two specific areas examined were the consular name (which indicates the date) with the words 'GEMIN', and an analysis of the letters in the word 'C FUF"O'. In the following fragment two classicists, Axel and Colin identify another potentially atypical letter. Axel is questioning the initial reading of the letter ' $F$ ' made this time, not by Vollgraff, but by his colleague, Rupert who is not present. 


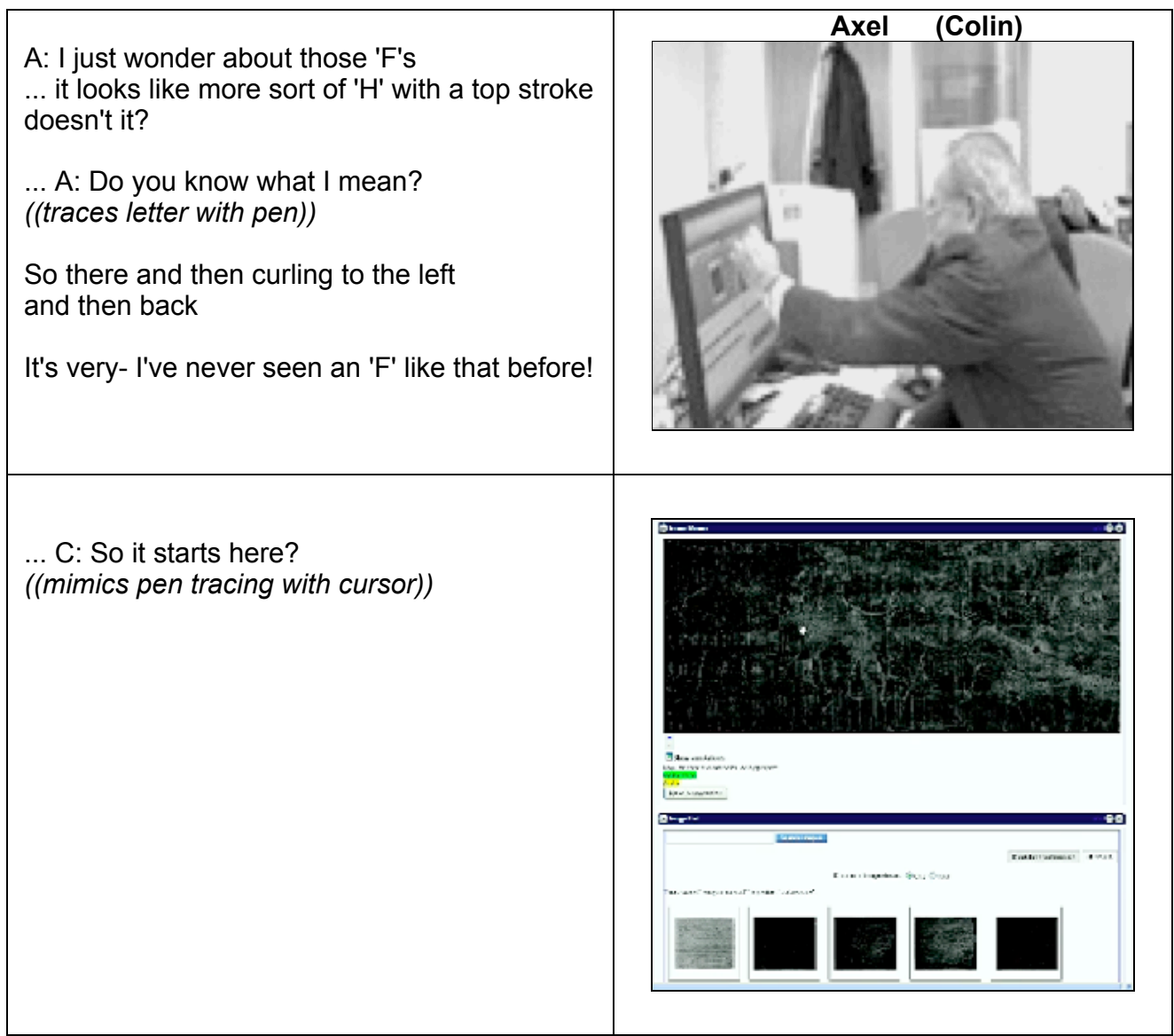

Figure 9. Identifying a letter-form.

Prior to his tracing the letter, Axel makes a comment about the it; 'I just wonder about those 'F's ... it looks like more sort of an ' $\mathrm{H}$ ' with a top stroke doesn't it?'. From this initial remark Axel proceeds to draw a mock-up on a piece of paper of how he sees the letter. Upon completing the drawing he shows the proposed letter shape to Colin, after which they both shift their orientation from the paper to the digital image of the manuscript within the VRE workspace. Axel then traces over the digital image in the workspace with his pen and concludes with; 'I've never seen an ' $F$ ' like that before'. Using the VRE the classicists successfully examine a letter-form previously identified as one letter and suggest an alternative reading. This is achieved not only through drawing, but in a similar manner as when analysing the projected image, through gesture and tracing. 
After Axel finishes his final annotation of the word 'FUF"O' he types into the system:

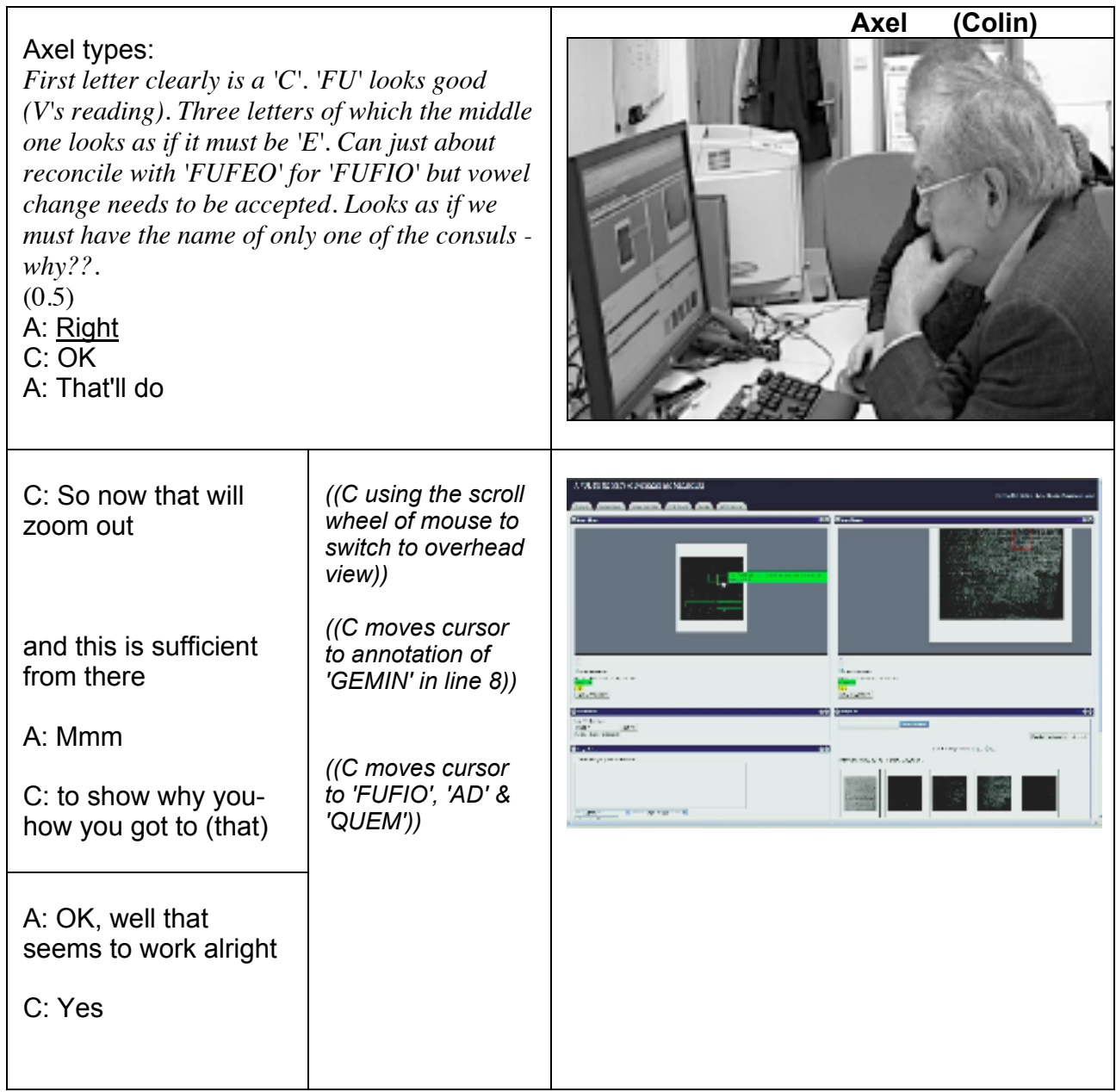

Figure 10. Viewing the image as a whole.

Following Axel's typing of the final annotation, Colin switches to the overhead view of the digital image and points to each annotation within it using the cursor. He hovers the cursor over the words - 'GEMIN' and 'FUFIO' and then over the words 'AD' and 'QUEM'. As he does this, Colin talks through how the overhead feature may be used to 'show why you- how you got to (that)': in other words, how each annotation relates to the other. The scholars use this feature to view, at a glance, annotations within the manuscript in relation to each other and to the text around them (Figure 11). In this way, researchers can view gaps as well as relationships between words in an emerging re-translation. They can also view how a re-interpreted word in one area may have implications for the reinterpretation of a word in another area of the text. 


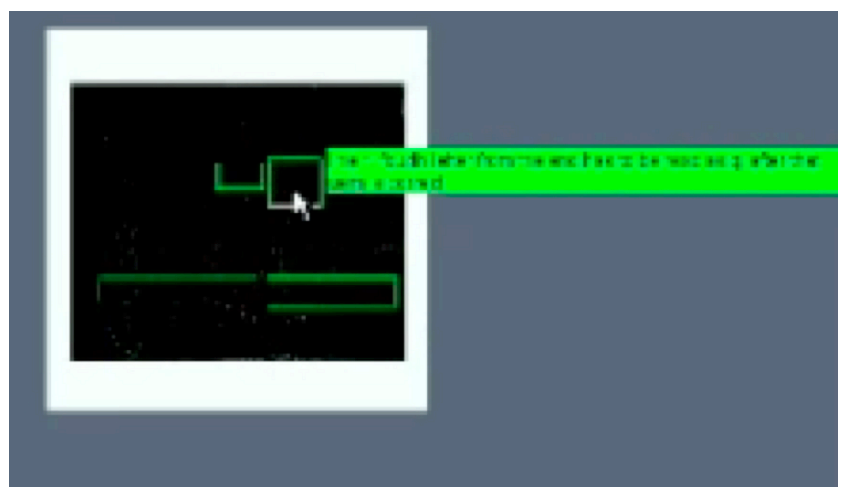

Figure 11. Overhead view of the annotated digital image.

In our observations of the classicists' use of the VRE, the work of analysing the text was achieved primarily through the annotation tool. Using this basic functionality they were able to identify and mark a letter within a digital image and consider alternative letter-forms. Indeed, the classicists were not only able to re-interpret the text in question but to come to a completely different reading of the Tolsum Tablet. In addition, the new reading had little to do with oxen, taxation or the revolt reported by Tacitus, they could also report something more significant, a new analysis of the letter forms produced at the time. Their analysis led to joint publications reporting these findings (Bowman et al, 2009).

Drawing from classicists' comments after using the prototype and continued analysis of their practices we are now considering further developments of the system. For example, software designers are investigating the development of hypothesis folders whereby researchers can store and track claims made by colleagues regarding particular texts. This would allow scholars to associate specific digital images of a manuscript with claims that have been made about a part of the text. Moreover, the software designers are seeking to develop functionality that enables scholars to annotate parts of an image so that they can record and store their reasoning about letters, words and groups of words and would allow them to be returned to either in the same period of work, or later. Such annotations may be listed chronologically and threaded in order to provide a trace of the reasoning whilst also being able to tag groups of the annotations together.

Our analysis of the classicists' practices has revealed just how complex the annotation functionality would need to be in order to properly address the needs of documentary scholars. Far from the basic, originally envisaged (and discussed) functionality of drawing a rectangular box around an area of an image and writing text that would appear once scrolled over the selected area, it became clear that scholars were working in a much more sophisticated manner and that the requirements for this part of the VRE needed far more consideration than originally planned. Although the need for private workspaces and collaborative projects were envisaged from the start, differing levels of notes and annotations such as 'dialogues' (private conversations), 'working papers' (not for publication 
but collaborative and explorative) and 'publication' (comments and annotations to be published for all to see) only came to light in observing their discussions and the three scholars at work.

Interestingly, both our analyses of the in situ production of collaborative interpretive practices and previous studies which sought to extract the classicists' knowledge using verbal protocols (Terras, 2006) suggests that the classicists' perception of the visual traces on the image is informed by the knowledge they've acquired within their community of expertise. The ways in which the classicists work with paper mock-ups in association with gesture suggests that a further resource is needed that would allow them not only to reproduce marks and annotations, but also these gestures over images. What appears critical to preserve, for the production of collaborative interpretations, are the tangible qualities of demonstrating to other participants the shape and form of letters.

Each of the fragments discussed in this paper suggest that their identification of atypical letters is informed through an analysis of the scribe's hand and by their historical knowledge of changes in writing styles throughout the 1st - 4th centuries. In this way, a concern for the context in which the manuscript was written and the ways in which each part within their analysis contributes to their interpretation of the text as a whole is always present, even in their detailed analysis of the visual traces that might form letters. Even though their visual perception of markings that reside within the digital images is mediated by technologies that enhance the manuscript, their interpretation of the text cannot be achieved without their expertise in Latin, Roman History, Papyrology, Palaeography and other areas in the Classics. In addition to these, they also rely upon their ability to identify variations in handwriting and to imagine how letter combinations may form intelligible words.

We observed the classicists frequently shifting between very local views of a mark or a letter to more general considerations of the characters next to it or another like it, even on the other side of the tablet. Also, the participants seem to have some difficulty locating lines of text when they are magnified and projected on to a large screen. Magnification tends to impair collaborative activities, for example, when they need to point at a mark that differs considerably in scale from that of the original. One simple suggestion emerging from the analysis is to provide a mechanism for annotating the images with line numbers to indicate which line of text the words under analysis relate to (cf. Figure 1). A more complex solution may be to provide the ability to magnify and zoom into areas of an image without replacing or obtruding the original view (as many zooming functions in existing image viewing applications tend to do). Rather, the tool should provide for an explicit 'Gestalt switch' where some device akin to a magnifying glass could be designed so that the non-magnified areas of the image would remain visible alongside the magnified area (Ware \& Lewis, 1995). In this 
way, the technology may support the juxtaposition of detailed views of marks and letter-forms with the wider geography of the text.

The new image processing techniques described go some way to removing the effects of the manuscript's damage and allow the classicists to identify markings more clearly and most importantly to see and read the text that resides within it. Additionally, embedded within the VRE are the computational resources of the National Grid Service (NGS) that allow for fast image processing tools to be accessed by the classicists so that they may work on texts by themselves or in collaboration with colleagues in real-time. Providing enhanced images in digital form has highlighted that we are concerned with more than just an image or text in this setting - but also the historical context of manuscripts. This suggests a whole range of features that could be associated with the identification of markings, letters and words in these manuscripts, but more in terms of the scribe's production of them. Indeed, the project is currently working on the provision of a system for palaeographical databases of letter-forms.

It has been suggested, that systems designed to support interpretive practices may need to focus primarily on the development of functionality that supports collaboration through digitally linking transcribed texts to their associated digital images, as well as provide the ability to track claims, evidence and arguments made by a group of collaborative researchers (Keeler, 2002). Rather than focusing the technology on the linking of materials or even on the automatic recognition of markings and letter-forms extracted from a database, it may be more important to endeavour to preserve some of the interpretive practices and discussions produced by the classicists as their identification of letters, words and the meaning of the text emerges. This might be envisaged as a more sophisticated form of annotation that could be made available to scholars. For example, the technology could resonate with their practices by adding assistance to the interpretive process. This assistance might indicate the consequences of such a change in the reading of a letter not only elsewhere in the text being analysed, but also in other related ancient manuscripts. This shifts the focus of the technological support from automated interpretation to augmented annotation. It also requires a shift in the kinds of collaborative support being envisaged: from the sharing of data and the communication results however tentative, to access to the emergent development of an interpretation.

\section{Discussion}

From the beginning of these research programmes, the e-Science and CI vision has sought to transform scientific practice by bringing together large teams of interdisciplinary researchers to work together to solve particular scientific problems (Hey \& Trefethen, 2003). This vision tends not only to be concerned with changing the dynamics of science but also with providing technologies that 
will facilitate the emergence of new forms of scientific practice. Collaboration is fundamental to supporting this form of large-scale scientific research. Typically, a critical aspect of such collaborative scientific enterprises includes the ability to provide access to very large data collections, very large scale computing resources and high performance visualization.

As more technologies have been developed and assessed in practice, we have seen a turn to supporting other kinds of research practices in non-scientific domains. In this paper we have considered the Classics, a field in the Humanities that has previously been characterised as a discipline perhaps dominated by a more solitary view of scholarly practice. This paper has shown how e-Research applications, even if only simply presented, can support collaboration between researchers. The simple projection of images enhanced by sophisticated processing was shown to facilitate collaboration.

A concern of the VRE programme and other initiatives in e-Research has been to explore the implications for communities of scholars who may be collaborating remotely; where scholars in the field may be working on the production and publication of intermediate findings rather than a final polished publication. Indeed, the proponents of the VRE considered here are not only concerned with enabling researchers to work with documents in new ways through the integration of image processing, viewing, annotation and real-time collaboration, but also in the future, to provide the potential for speeding up the publishing process of scholars. In the past, a text may be deciphered by an individual over a period of time and published only when they have had the time to write up the entire process, the collaborative aspects of the VRE may allow not only for a reading to be discussed and deliberated by as many colleagues as one might wish, but, in addition, might also enable the reading of the text to be published immediately with the individual credited for their work prior to print publication. Such a scenario may indeed increase the speed at which scholars discuss or comment on each others' work and provide the potential for researchers to share their expertise and knowledge on a global scale.

The contribution of e-Research tools however, may not be best viewed as replacing or radically transforming current modes of publication. For example, in our study, the classicists who collaborated together made relevant discoveries that have since been published in joint publications (Bowman et al, 2009). The most appropriate way to present these findings, within the context of interpretation, at present still appears to be the academic paper: a method that presents complex forms of linking and annotation, but not quite of the kind provided in the envisaged infrastructures. However, introducing more modest interventions such as the ones described here in conjunction with a detailed analysis of it use may suggest further ways in which to reconfigure research collaborations.

This study has drawn upon the tradition of workplace studies, quite familiar to researchers in CSCW. Naturalistic studies of the activities of practitioners were 
undertaken and the materials were analysed to reveal the details of the practices and interactions between those participants. In CSCW, such workplace studies have frequently been drawn upon to suggest requirements for technologies and even, in some cases, implications for design. Notwithstanding concerns with the challenges of deriving requirements or designs from detailed studies of practice (cf. Plowman et al 1995, Dourish 2006), a strict adherence to undertaking a workplace study prior to design can sit uncomfortably with aspects of the oftcriticised waterfall model of system development. Over the last decade or so within CSCW, HCI and elsewhere a more innovative approach has emerged involving a closer integration of studies of the use of technologies with other design activities. These often involving drawing from naturalistic studies to inform some technological intervention in the participants' setting. (e,g, Blomberg et al, 1996, Gaver et al, 1999, Hutchinson et al, 2003),

In this study we take a slightly different approach. Rather than seeing naturalistic studies and software development in terms of phases or activities where one informs the other - they often occurred in parallel. Thus we video recorded: teaching sessions where students were learning the skills and practices of reading and interpreting ancient papyri; co-present analysis sessions where scholars used enhanced digital images to conduct collaborative readings; and quasi-naturalistic experiments with prototype systems. These were then analysed in similar ways focusing on the moment-to-moment production of activities in interaction. Such an approach might be termed as a 'thin slice deep cut' process where relatively short-term periods of data collection are conducted, often relying on small fragments and where key activities are subject to detailed analysis. This analysis focuses on the interactional organisation of collaborations and the details of the skills and practices that participants draw upon to do their scholarly work. However, unlike many domains, research settings are often conducive to experimentation. It is perhaps feasible to intervene and undertake studies where prototype technologies that contain representative features are actually used in situ. In such cases, naturalistic studies, or perhaps more accurately quasinaturalistic studies can provide resources for systematic analysis and also inform the future development and deployment of technological infrastructures.

Despite the great potential of cyberinfrastructures and tools for e-Research, significant challenges remain when trying to deploy these technologies to support the everyday work practices of researchers. Not only do designers face the familiar problems of developing technologies that match the requirements of users, that include considerations of the ways they work, but also the additional challenges of identifying the needs of researchers that may be very specific, relating to the distinctive nature of a particular research project or the particular materials they are work with. Therefore, it can be difficult to match the demands of developing large infrastructures with the specific needs of researchers. Even a minor delay in making a prototype available for a particular programme of 
research can undermine its effectiveness. It may be that smaller scale and more focused initiatives might support the uptake and use of e-Research tools. Rather than focus projects on the development of large-scale infrastructures, which might be perceived as being somehow imposed upon a research domain; we might proceed more modestly, by developing smaller, modular systems that reflect the needs of researchers. These prototypes could then be introduced into a work setting as 'technical interventions' and evaluated at the location of work in order to develop a more detailed understanding of the disciplinary concerns of the researchers and how they collaboratively use the system in actual practice. This type of approach requires distinctive changes, contributions and cooperation to the design process itself; from developers of middleware and applications, to designers of interfaces and interaction. The grand challenge for e-Research, however, may be more in bringing together contributions from computer science with those of two distinct areas of social science, which have hitherto addressed quite different issues, one concerned with how scientific knowledge is produced and disseminated and the other with the details of work practice and collaboration.

\section{Acknowledgments}

We would like to thank Alan Bowman, Mike Brady, Charles Crowther, Roger Tomlin, Melissa Terras and Segolene Tarte of the VRE for the Study of Ancient Documents (VRE-SDM) and the e-Science and Ancient Documents (eSAD) projects. This research was supported by Embedding e-Science Applications - Designing and Managing for Usability project. Grant No. EP/D049733/1.

\section{References}

Atkins, D. (2003): Revolutionizing Science and Engineering Through Cyberinfrastructure: Report of the National Science Foundation. Blue-Ribbon Advisory Panel on Cyberinfrastructure. January 2003.

Blomberg, J. L., Suchman, L., \& Trigg, R. (1996): Reflections on a Work-Oriented Design Project. Human-Computer Interaction, vol.11, pp. 237-265.

Bowman, A, Tomlin, R. \& Worp, K. (2009): Emptio Bovis Frisica: The 'Frisian ox sale' reconsidered. Journal of Roman Studies, vol. 99, pp. 156-70.

Bowman, A, Crowther C, Kirkham, R, \& Pybus J. (2008): Virtual Research Environment for the Study of Documents and Manuscripts. The Oxford e-Research Conference, 11-13 Sept. 2008. Oxford, UK.

Bowman, A. \& Tomlin, R. (2005): Wooden stilus tablets from Roman Britain. In Bowman, A.. \& Brady, M. (eds.), Images and artefacts of the ancient world. Oxford University Press, Oxford, pp. 7-14.

Brown, B., \& Perry, M. (2002): Of maps and guidebooks: designing geographical technologies. In Proc. of the 4th conference on Designing interactive systems: processes, practices, methods, and techniques. pp. 28-32. 
Carusi, A. (2006): Textual Practitioners: A comparison of hypertext theory and phenomenology of reading. Arts and Humanities in Higher Education, vol. 5, pp. 163-180.

Crabtree, A., Hemmings, T., \& Rodden, T. (2002): Pattern-based support for interactive design in domestic settings. In Proc. of the 4th conference on Designing interactive systems: processes, practices, methods, and techniques. pp. 265-276.

Dourish, P. (2006): Implications for Design. In Proc. of ACM CHI 2006, (CHI '06) (Montreal, Ontario, April 22-27, 2006), pp. 541-550.

de la Flor, G., Luff, P., Jirotka, M., Pybus, J., Kirkham, R., Carusi, A. (2010): The Case of the Disappearing Ox: Seeing Through Digital Images to an Analysis of Ancient Texts, In Proc. 28th ACM Conference on Human Factors in Computing Systems, CHI 2010, Atlanta GA, USA.

Foster, I. \& Kesselman, C. (eds.) (2004): The Grid: Blueprint for a New Computing Infrastructure. San Francisco, CA: Morgan Kaufmann.

Garfinkel, H., Lynch, M. and Livingston, E. (1981): The Work of Discovering Science Construed with Materials from the Optically Discovered Pulsar. Philosophy of the Social Sciences, vol. 11, no. 2, pp. 131-158.

Garfinkel, H. (1967): Studies in ethnomethodology. Prentice-Hall, Englewood Cliffs, NJ, USA.

Gaver, B., Dunne, T., \& Pacenti, E. (1999): Design: Cultural probes. interactions. Interactions, vol. 6 , no. 1, pp. 21-29.

Hutchinson, H., Mackay, W., Westerlund, B., Bederson, B., B., Druin, A., Plaisant, C., et al. (2003): Technology probes: inspiring design for and with families. In Proc. of the SIGCHI conference on Human factors in computing systems, Ft. Lauderdale, Florida, USA: ACM Press, pp. 17-24.

Keeler, M. (2002): The Place of Images in a World of Text. Computers and the Humanities, vol. 36, pp. 75-93.

Goodwin, C. (1995): Seeing in depth. Social studies of science vol. 25, pp. 237-274.

Goodwin, C. (1994): Professional vision. American Anthropologist vol. 96 no. 3, pp. 606-633.

Hey, T., Tefethen, A. (2003): e-Science and its Implications. Philosophical Transactions of the Royal Society A, vol. 361. pp. 1809-1825.

Luff, P, Hindmarsh, J. and Heath, C (2000): (Eds) Workplace Studies: Recovering Work Practice and Informing System Design. Cambridge: Cambridge University Press.

Luff, P., Heath, C., Kuzuoka, H., Yamazaki, K., \& Yamashita, J. (2006): Handling Documents and Discriminating Objects in Hybrid Spaces. In Proc. of ACM CHI 2006, (CHI '06) (Montreal, Ontario, April 22-27, 2006), pp. 561-570.

Lynch, M. (1985): Discipline and the material form of images: An analysis of scientific visibility. Social studies of science, vol. 15, pp. 37-66.

Meyer, E., Schroeder, R., Dutton, W. (2008): The Role of e-Infrastructures in the Transformation of Research Practices and Outcomes. In iConference 2008. (available at: [http://www.ischools.org/oc/conference08/pc/PA10-2_iconf08.pdf]; last accessed 16 March 2010).

Molton, N., Pan, X., Brady, M., Bowman, A, Crowther, C., \& Tomlin, R. (2003): Visual enhancement of incised text. Pattern Recognition, vol. 36, pp.1031-1043.

Plowman, L., Rogers, Y., \& Ramage, M. (1995): What are Workplace Studies For? In Proc. of the European Conference on Computer-Supported Cooperative Work (ECSCW'95), Stockholm, Sweden, Kluwer, Dordrecht, The Netherlands.

Roued Olsen, H., Tarte, S, Terras, M., Brady, M. \& Bowman, A. (2009): Towards an interpretation support system for reading ancient documents. Digital Humanites'09 July 2009, pp. 237-39. 
Sacks, H. (1992): Lectures in Conversation: Volumes I and II. Oxford: Blackwell.

Sharrock, W. and Coulter, J. (1998): On What We Can See. Theory and Psychology, vol. 8, no.2, pp. 147-164.

Suchman, L. (1987): Plans and situated actions: the problem of human-machine communication. Cambridge University Press.

Swan, L., Taylor, A. S., \& Harper, R. (2008): Making place for clutter and other ideas of home. ACM Trans. Comput.-Hum. Interact, vol. 15, no.2, pp. 1-24.

Tang, J. C., \& Minneman, S. L. (1991): VideoDraw: A Video Interface for Collaborative Drawing. ACM Transactions on Information Systems, vol. 9, no. 2, pp. 170-184.

Tarte, S. (2009): Papyrological Investigations: Transferring Perception and Interpretation into the Digital World, Working paper.

Taylor, J. (2001): News from the e-Science Programme: first phase of the programme. RCUK website, (available at: [http://www.rcuk.ac.uk/escience/news/firstphase.htm]; last accessed 16 March 2010).

Terras, M.M. (2006): Image to interpretation: towards an intelligent system to aid historians in the reading of the Vindolanda texts. Oxford University Press UK.

Unsworth, J. (2006): Our Cultural Commonwealth: The Report of the American Council of Learned Societies Commission on Cyberinfrastructure for the Humanities and Social Sciences http://www.acls.org/cyberinfrastructure/OurCulturalCommonwealth.pdf and the Bamboo Planning Project http://projectbamboo.org/.

vom Lehn, D., Heath, C., \& Hindmarsh, J. (2001): Exhibiting Interaction: Conduct and collaboration in museums and galleries. Symbolic Interaction, vol. 24, no. 2, pp. 189-216.

Ware, C. and Lewis, M. (1995): 'The DragMag image magnifier', CHI 1995, Denver, pp. 407-408.

Warr A., de la Flor, G. Jirotka, M. and S. Lloyd. (2008): Usability in e-science: The eDiaMoND case study. In CHI workshop on Increasing the Impact of Usability Work in Software Development, San Jose, USA, 2008. 